\title{
Retraction
}

\section{Retracted: Biomedical Implications of Heavy Metals Induced Imbalances in Redox Systems}

\author{
BioMed Research International \\ Received 5 November 2020; Accepted 5 November 2020; Published 21 December 2020 \\ Copyright (c) 2020 BioMed Research International. This is an open access article distributed under the Creative Commons \\ Attribution License, which permits unrestricted use, distribution, and reproduction in any medium, provided the original work \\ is properly cited.
}

BioMed Research International has retracted the article titled "Biomedical Implications of Heavy Metals Induced Imbalances in Redox Systems" [1]. The article was found to contain a substantial amount of material, without citation, from previously published articles, including the following sources:

(i) Danyal Ibrahim, Blake Froberg, Andrea Wolf, Daniel E. Rusyniak. "Heavy Metal Poisoning: Clinical Presentations and Pathophysiology", Clinics in Laboratory Medicine, 2006. 10.1016/j.cll.2006.02.003. [2]

(ii) Robert A. Goyer and Thomas W. Clarkson, "Toxic Effects of Metals," in casarett \& doull's toxicology the basic science of poisons, 6th ed, Curtis D. Klaassen. https://www.biologicaldiversity.org/campaigns/ get_the_lead_out/pdfs/health/Goyer_1996.pdf. [3]

(iii) "Systems Biology of Free Radicals and Antioxidants", Ismail Laher, Springer Nature, 2014. 10.1007/978-3642-30018-9. [4]

(iv) Wikipedia contributors, "Mercury poisoning," Wikipedia, The Free Encyclopedia, https://en.wikipedia .org/w/index.php?title=Mercury_poisoning\&oldid= 919871578 (accessed April 11, 2019). [5]

(v) Jörg B. Schulz Allen I. Arieff, "Metabolic and Toxic Encephalopathies" in Neurological Disorders 2nd ed, Thomas Brandt, Louis R. Caplan, Johannes Dichgans, Christoph Diener Christopher Kennard, 2003. 10.1016/B978-012125831-3/50267-7. [6]

\section{References}

[1] B. Sharma, S. Singh, and N. J. Siddiqi, "Biomedical Implications of Heavy Metals Induced Imbalances in Redox Systems," BioMed Research International, vol. 2014, Article ID 640754, 26 pages, 2014.

[2] D. Ibrahim, B. Froberg, A. Wolf, and D. E. Rusyniak, "Heavy Metal Poisoning: Clinical Presentations and Pathophysiology," Clinics in Laboratory Medicine, vol. 26, no. 1, pp. 67-97, 2006.

[3] R. A. Goyer and T. W. Clarkson, "Toxic Effects of Metals," casarett \& doull's toxicology the basic science of poisons6th edition, https://www.biologicaldiversity.org/campaigns/get_the_ lead_out/pdfs/health/Goyer_1996.pdf.

[4] I. Laher, Ed., Systems Biology of Free Radicals and Antioxidants, Springer Nature, 2014.

[5] Wikipedia contributors, Mercury poisoningWikipedia, The Free EncyclopediaApril 2019, https://en.wikipedia.org/w/index .php?title=Mercury_poisoning\&oldid=919871578.

[6] J. B. Schulz and A. I. Arieff, "Metabolic and Toxic Encephalopathies," in Neurological Disorders, T. Brandt, L. R. Caplan, J. Dichgans, C. Diener, and C. Kennard, Eds., . 